\title{
Coronary arteriographic study of mild angina
}

\author{
W. Walsh, A. F. Rickards, and R. Balcon \\ From the National Heart and Chest Hospitals, London Chest Hospital, London
}

The results of coronary arteriography, exercise, and pacing stress testing in 50 young patients with mild angina are analysed. There was a significant correlation between the results of stress tests and the severity of disease. There were, however, patients with severe disease and negative tests. Fifty-six per cent of patients had disease which potentially could have been surgically treated. It is concluded that coronary arteriography is indicated in these patients with mild symptoms.

There has been a reappraisal of the indications for coronary arteriography with the advent of coronary arterial bypass surgery. While disabling angina unresponsive to medical therapy is the common indication for coronary arteriography, it remains controversial whether patients with mild angina require arteriographic study.

There have been several reports recently directly relating arteriographic severity of coronary artery disease to prognosis (Friesinger, Page, and Ross, 1970; Bruschke, Proudfit and Sones, 1973a, b; Oberman et al., I973). Prognosis is most favourable with normal coronary arteriograms, and is progressively worse as the number of coronary arteries affected by major disease increases. Moreover, it has been suggested recently that coronary arterial surgery may improve the prognosis in patients with double or triple vessel disease (Sheldon et al., 1973).

It seemed desirable, therefore, to assess arteriographically the severity of the coronary arterial disease in patients with mild angina, perhaps especially in the younger age groups, who at present tend to be managed conservatively. We decided on a policy of arteriography in these patients but, because of limitations of facilities, arbitrarily chose to investigate only patients of 50 years or less in the first instance.

\section{Methods}

The grading of angina used was similar to the New York Heart Association grading for dyspnoea. Grade I was angina occurring with strenuous exertion only (e.g. running for a bus). Grade II was angina occurring with a moderate degree of exertion (e.g. walking quickly) but not limiting ordinary physical activity.

Received 16 December 1974.
Patients who presented with severe angina but who had, with beta-adrenergic blockade therapy, improved to grade I and II were excluded.

Each patient had a conventional I2-lead electrocardiogram.

A graduated exercise test was performed on a bicycle ergometer while a bipolar chest lead electrocardiogram was monitored. The test was stopped at the development of typical chest pain, of ST segment abnormalities on the electrocardiogram, or of exhaustion. Criteria for a positive test were the development of typical chest pain or I mm horizontal depression of ST segments.

Cardiac pacing using a bipolar catheter in the right atrium or right ventricle was performed before coronary arteriography. The heart rate was increased in increments of Io beats per minute until either the patient developed chest pain (positive test) or a maximum of 180 beats per minute was reached (negative test).

Left heart catheterization was performed via a brachial arteriotomy using a multiple side-hole catheter for measurement of left ventricular end-diastolic pressure and for ventriculography.

Coronary arteriography was performed using the Sones technique. $35 \mathrm{~mm}$ cine film was taken in at least 2 oblique projections for each vessel.

The severity of the coronary artery lesion was graded $O$, I, II, grade $O$ being a normal vessel, grade I a minor stenosis $(<75 \%)$, and grade II a major stenosis $(>75 \%)$ or occlusion.

The left ventriculogram was graded on a scale $\circ$ to 4 . Grade $O$ represents normal contraction, grades $I, 2$, and 3 segments of dyskinetic wall of increasing size, and grade 4 diffuse dyskinesia.

Fifty patients, aged 50 years or less, with grade I or II angina of effort were studied between July I97I and July 1973. Most of the patients were studied in the last 12-month period.

Statistical analysis was performed by using a multicell $\chi^{2}$ test and an unpaired Student t-test with small sample corrections. 
TABLE I

\begin{tabular}{|c|c|c|c|c|c|c|c|c|c|c|c|c|c|}
\hline \multirow{3}{*}{$\begin{array}{l}\text { Case } \\
\text { No. } \\
\mathrm{I}\end{array}$} & \multirow{3}{*}{$\begin{array}{l}\text { Age } \\
(y r)\end{array}$} & \multirow{3}{*}{$\begin{array}{l}\text { Sex } \\
M\end{array}$} & \multirow{2}{*}{\multicolumn{2}{|c|}{$\begin{array}{l}\text { Angina: } \\
\text { grade } \\
\text { (duration) } \\
(\text { mth) }\end{array}$}} & \multirow{2}{*}{\multicolumn{2}{|c|}{$\begin{array}{l}\beta \text {-blocking drug } \\
\text { dose (mg) }\end{array}$}} & \multirow{3}{*}{$\begin{array}{l}\begin{array}{l}\text { Previous } \\
\text { infarct } \\
(E C G)\end{array} \\
\text { Anterior }\end{array}$} & \multirow{3}{*}{$\begin{array}{l}\begin{array}{l}\text { Exercise } \\
\text { test }\end{array} \\
+\end{array}$} & \multirow{3}{*}{$\begin{array}{l}\begin{array}{l}\text { Pacing } \\
\text { test }\end{array} \\
-\end{array}$} & \multicolumn{3}{|c|}{$\begin{array}{l}\text { Coronary artery } \\
\text { score }\end{array}$} & \multirow{3}{*}{$\begin{array}{l}\begin{array}{l}\text { Left } \\
\text { ventriculo- } \\
\text { gram }\end{array} \\
2\end{array}$} \\
\hline & & & & & & & & & & \multirow{2}{*}{$\frac{L A D}{\mathrm{I}}$} & \multirow{2}{*}{$\frac{C X}{2}$} & \multirow{2}{*}{$\frac{R C A}{2}$} & \\
\hline & & & II & (2) & Propranolol & 120 & & & & & & & \\
\hline 2 & 46 & $\mathbf{M}$ & II & (3) & Practolol & 600 & Inferior & + & + & 2 & 0 & 2 & I \\
\hline 3 & 30 & $\mathbf{M}$ & I & (3) & 0 & 0 & $\mathbf{N}$ & - & - & 0 & 0 & 0 & 0 \\
\hline 4 & 36 & $\mathbf{M}$ & I & (3) & Propranolol & 120 & $\mathbf{N}$ & - & + & 0 & 0 & 0 & 0 \\
\hline 5 & 34 & $\mathbf{M}$ & I & (3) & 0 & 0 & $\mathbf{N}$ & - & + & 0 & 2 & 2 & $\mathbf{I}$ \\
\hline 6 & 38 & $\mathbf{M}$ & II & (2) & Propranolol & 120 & RBBB & - & NP & 0 & 0 & 0 & 0 \\
\hline 7 & 30 & $\mathbf{F}$ & II & (6) & Propranolol & 120 & Inferior & + & - & 0 & 0 & 0 & 0 \\
\hline 8 & 49 & $\mathbf{M}$ & I & (3) & Propranolol & 120 & Inferior & + & + & I & 2 & 2 & 2 \\
\hline 9 & 46 & $\mathbf{M}$ & II & (3) & Propranolol & 120 & Inferior & + & + & I & $\mathbf{I}$ & 2 & 0 \\
\hline Io & 42 & $\mathbf{M}$ & II & (7) & Propranolol & 120 & Inferior & - & + & 2 & 2 & I & I \\
\hline II & 38 & $\mathbf{M}$ & I & (I) & 0 & 0 & Inferior & + & - & 2 & 0 & 2 & 3 \\
\hline 12 & 39 & $M$ & II & (6) & Propranolol & 120 & $\mathbf{N}$ & + & + & 0 & 0 & 0 & 0 \\
\hline 13 & 34 & $\mathbf{M}$ & II & (36) & 0 & 0 & $\mathbf{N}$ & + & + & 2 & 2 & 2 & 0 \\
\hline 14 & 49 & $\mathbf{M}$ & I & (24) & 0 & 0 & $\mathbf{N}$ & - & - & 0 & 0 & 0 & 0 \\
\hline 15 & 42 & $\mathbf{M}$ & II & $(8)$ & 0 & 0 & Anterior & + & + & 2 & 2 & 2 & 3 \\
\hline 16 & 50 & $\mathbf{M}$ & I & (6) & 0 & 0 & $\mathbf{N}$ & - & - & I & I & $\mathbf{I}$ & 0 \\
\hline 17 & 50 & $M$ & I & (36) & Practolol & 300 & $\mathbf{N}$ & - & + & 2 & 2 & $\mathbf{I}$ & 0 \\
\hline 18 & 40 & $\mathbf{M}$ & I & (12) & Propranolol & 120 & $\mathbf{N}$ & - & + & 2 & 2 & 2 & I \\
\hline 19 & 50 & $\mathbf{M}$ & II & $(8)$ & Propranolol & 120 & Anterior & + & + & 2 & I & I & 0 \\
\hline 20 & 48 & $\mathbf{M}$ & II & (12) & Practolol & 300 & $\mathbf{N}$ & + & + & 2 & 2 & 2 & 0 \\
\hline 21 & 42 & $\mathbf{M}$ & II & $(48)$ & Propranolol & 120 & $\mathbf{N}$ & + & + & 2 & 2 & 2 & I \\
\hline 22 & 30 & $\mathbf{M}$ & I & (24) & Practolol & 300 & $\mathbf{N}$ & + & + & 2 & 2 & I & 0 \\
\hline 23 & 44 & $M$ & I & (12) & Propranolol & 160 & $\begin{array}{l}\text { Anterior } \\
\text { and } \\
\text { inferior }\end{array}$ & + & + & 2 & 0 & I & 0 \\
\hline 24 & 47 & $\mathbf{M}$ & II & (4) & Propranolol & 120 & Anterior & + & - & 2 & 2 & 0 & 0 \\
\hline 25 & 43 & $\mathbf{M}$ & II & (I) & Practolol & 300 & $\mathbf{N}$ & NP & - & $\mathbf{I}$ & 2 & 2 & I \\
\hline 26 & 48 & $\mathbf{M}$ & I & (4) & Propranolol & 120 & $\mathbf{N}$ & + & - & 2 & I & 2 & 0 \\
\hline 27 & 50 & $\mathbf{M}$ & I & (18) & Practolol & 300 & $\mathbf{N}$ & + & - & 0 & 0 & I & 0 \\
\hline 28 & 37 & $\mathbf{M}$ & I & (18) & Propranolol & 120 & Inferior & + & + & 2 & 2 & 2 & 0 \\
\hline 29 & 47 & $\mathbf{M}$ & I & (2) & Propranolol & 120 & $\mathbf{N}$ & + & + & I & 0 & 0 & 0 \\
\hline 30 & 27 & $\mathbf{F}$ & I & (24) & Propranolol & 120 & $\mathbf{N}$ & - & - & 0 & 0 & 0 & 0 \\
\hline 31 & 45 & $\mathbf{M}$ & I & (15) & Practolol & 200 & Inferior & + & - & I & $\mathbf{I}$ & 2 & 0 \\
\hline 32 & 45 & $\mathbf{M}$ & I & (6) & Propranolol & 120 & $\mathbf{N}$ & - & - & 2 & 0 & $\mathbf{I}$ & 0 \\
\hline 33 & $4 I$ & $\mathbf{M}$ & II & (5) & Propranolol & 120 & $\mathbf{N}$ & - & - & 2 & I & 2 & 0 \\
\hline 34 & 45 & $M$ & II & (3) & 0 & 0 & $\begin{array}{l}\text { Anterior } \\
\text { and } \\
\text { inferior }\end{array}$ & + & + & I & 0 & 0 & 0 \\
\hline 35 & 40 & $\mathbf{M}$ & II & (6) & Propranolol & 160 & $\mathbf{N}$ & - & + & 0 & 0 & 0 & 0 \\
\hline 36 & 45 & $\mathbf{M}$ & I & (48) & 0 & 0 & Inferior & + & + & 2 & 2 & 2 & 2 \\
\hline 37 & 42 & $\mathbf{F}$ & II & (3) & Propranolol & 120 & $\mathbf{N}$ & + & - & 0 & 0 & $\mathbf{I}$ & 0 \\
\hline 38 & 45 & $\mathbf{F}$ & II & (30) & Propranolol & 120 & $\mathbf{N}$ & + & + & 0 & 0 & 0 & 0 \\
\hline 39 & 45 & $\mathbf{M}$ & II & (7) & Propranolol & 160 & $\mathbf{N}$ & + & - & 0 & 0 & 0 & 0 \\
\hline 40 & 49 & $\mathbf{M}$ & II & (3) & Practolol & 600 & $\begin{array}{l}\text { Anterior } \\
\text { and } \\
\text { inferior }\end{array}$ & - & - & 2 & 0 & 0 & 0 \\
\hline $4 I$ & 42 & $\mathbf{M}$ & II & (30) & Propranolol & 240 & Anterior & + & + & 2 & 0 & 2 & 2 \\
\hline 42 & $4 I$ & $\mathbf{M}$ & II & (12) & 0 & 0 & $\mathbf{N}$ & + & - & 0 & 0 & 0 & 0 \\
\hline 43 & 50 & $\mathbf{F}$ & II & (6) & Propranolol & 80 & $\mathbf{N}$ & + & - & 0 & 0 & 2 & 0 \\
\hline 44 & 24 & $\mathbf{M}$ & I & (2) & 0 & 0 & $\mathbf{N}$ & - & - & 0 & 0 & 0 & 0 \\
\hline 45 & 49 & $\mathbf{M}$ & I & (18) & Propranolol & 120 & $\mathbf{N}$ & + & - & $\mathbf{I}$ & 2 & I & 0 \\
\hline 46 & 50 & $\mathbf{M}$ & I & (36) & 0 & 0 & $\mathbf{N}$ & + & - & 2 & $\mathbf{I}$ & 0 & 0 \\
\hline 47 & 41 & $\mathbf{M}$ & II & (36) & 0 & 0 & Inferior & + & - & 2 & I & $\mathbf{I}$ & 0 \\
\hline 48 & 49 & $\mathbf{M}$ & I & (12) & 0 & 0 & Inferior & + & - & $\mathbf{I}$ & 2 & 2 & 0 \\
\hline 49 & 30 & $\mathbf{M}$ & I & (24) & 0 & 0 & $\mathbf{N}$ & + & + & 2 & 2 & 2 & 0 \\
\hline 50 & 50 & $M$ & $\bar{I}$ & (I) & 0 & 0 & Inferior & + & - & I & 0 & $\mathbf{I}$ & 0 \\
\hline
\end{tabular}

Abbreviations: $\mathrm{LAD}=$ left anterior descending ; $C X=$ circumflex $; \mathrm{RCA}=$ right coronary artery $; \mathrm{N}=$ normal ECG ; $\mathrm{NP}=$ not performed. 


\section{Results}

The clinical and arteriographic findings are summarized in Table 1 . There were 45 men and 5 women. The average age was 42.5 years (range 24 to 50).

The duration of symptoms varied from I to 48 months, with a mean of 13 months.

Thirty-four of the patients $(68 \%)$ were receiving beta-adrenergic blocking agents; 8 were on practolol (average dose $363 \mathrm{mg}$ daily) and 26 on propranolol (average dose $130 \mathrm{mg}$ daily). The clinical grading refers to the pretreatment level of symptoms.

Ten of the patients $(20 \%)$ had a documented history of past myocardial infarction; however, 20 patients $(40 \%)$ had electrocardiographic evidence of previous infarction ( $Q$ waves and/or persisting inverted $T$ waves). Five patients had a pattern of anterior infarction, 12 had inferior infarction, and 3 had both anterior and inferior infarction. One patient had right bundle-branch block. Forty-eight patients had both exercise and pacing tests; 34 $(69 \%)$ of the 49 exercise tests and $24(49 \%)$ of the 49 pacing tests were positive.

Cardiac catheterization was performed on all patients without any major complications. Twelve patients $(24 \%)$ had normal coronary arteries and 6 (12\%) had minor disease (grade I) only. In the remaining 32 patients there were 62 major lesions of the coronary arteries; 23 in the left anterior descending $(46 \%)$, I8 in the circumflex artery $(36 \%)$, and $21(42 \%)$ in the right coronary artery.

Of the 5 female patients, 3 had normal vessels, and 2 had disease of the right coronary artery, I major and I minor. Thirty-eight patients had a normal ventriculogram ( $76 \%$ ). Two patients had a major dyskinesis of the left ventricle, one with double vessel disease, and one with triple vessel disease. The other ro patients had only mild degrees of left ventricular dyskinesis.

\section{Arteriographic analysis}

Table 2 represents a more detailed analysis of the arteriographic findings. Patients were subdivided according to the number of vessels involved with major disease.

Eighteen patients $(36 \%)$ had normal or minimally diseased coronary arteries, Io (20\%) had single vessel disease only, I4 (28\%) double vessel disease, and $8(16 \%)$ had triple vessel disease. Hence 44 per cent of patients with non-limiting angina had double or triple vessel disease.

Of the Io patients with single vessel disease the left anterior descending artery was involved in 6, the circumflex artery in $I$, and the right coronary artery in 3. There were equal numbers of the 3 combinations possible in the patients with double vessel disease.

An attempt was made to determine any factors in the clinical findings which might help discriminate between the different groups. There was no significant association between the number of vessels involved, the presence of abnormal resting electrocardiogram, a positive exercise test or any combination of these 2 variables.

However, there was an association between the severity of coronary artery disease and a positive pacing test $\left(\chi^{2}=11.5, \mathrm{P}<0.01\right)$ and also the combination of a positive pacing and exercise test $\left(\chi^{2}=\right.$ II.2, $P<0.025$ ).

Those patients with triple vessel disease had a significantly longer duration of symptoms when compared with the group with normal vessels $(t=2.8 \quad P<0.01)$ but not when compared with patients with single or double vessel disease.

Patients were further divided according to whether they had potentially surgical (double and triple vessel) disease or non-surgical (normal, minimal, single) (Table 2). There were 28 patients in the first group and 22 patients in the second

TABLE 2 Correlation of angiographic and clinical findings

\begin{tabular}{|c|c|c|c|c|c|c|c|}
\hline $\begin{array}{l}\text { Severity of coronary } \\
\text { lesions }\end{array}$ & $\begin{array}{l}\text { No. of } \\
\text { patients }\end{array}$ & $\begin{array}{l}\text { Mean } \\
\text { duration } \\
\text { symptoms } \\
\text { (mth) }\end{array}$ & $\begin{array}{l}\text { Abnormal } \\
\text { resting } \\
\text { electro- } \\
\text { cardiogram } \\
(A)\end{array}$ & $\begin{array}{l}\text { Positive } \\
\text { exercise } \\
\text { test } \\
(B)\end{array}$ & $\begin{array}{l}\text { Positive } \\
\text { pacing } \\
\text { test } \\
(C)\end{array}$ & $\begin{array}{l}A, B, \text { and } C \\
\text { abnormal }\end{array}$ & $\begin{array}{l}A, B, \text { and } C \\
\text { normal }\end{array}$ \\
\hline $\begin{array}{l}\text { Normal and }<75 \%(1) \\
>75 \% \text { lesion of I vessel ( } 2) \\
>75 \% \text { lesions of } 2 \text { vessels ( } 3) \\
>75 \% \text { lesions of } 3 \text { vessels ( } 4) \\
1+2 \\
3+4\end{array}$ & $\begin{array}{r}18 \\
10 \\
14 \\
8 \\
28 \\
22\end{array}$ & $\begin{array}{r}8.8 \\
\text { I } 4.3 \\
\text { IO.3 } \\
25.8 \\
\text { I0.8 } \\
\text { J } 5.9\end{array}$ & $\begin{array}{r}4 \\
6 \\
8 \\
3 \\
10 \\
\text { I I }\end{array}$ & $\begin{array}{r}11 \\
8 \\
9 \\
7 \\
19 \\
16\end{array}$ & $\begin{array}{r}6 \\
3 \\
7 \\
8 \\
9 \\
15\end{array}$ & $\begin{array}{l}1 \\
3 \\
3 \\
3 \\
4 \\
6\end{array}$ & $\begin{array}{l}5 \\
1 \\
2 \\
0 \\
6 \\
2\end{array}$ \\
\hline
\end{tabular}


group. Only the result of the pacing test was significantly different in the 2 groups $\left(\chi^{2}=5.0\right.$, $P<0.05$ ).

\section{Discussion}

The rapid increase in the performance of coronary arteriography and direct coronary arterial surgery has greatly altered the management of patients with severe angina. Patients with mild non-disabling angina, however, generally have continued to be treated conservatively with nitroglycerin and a betaadrenergic blocking agent and are usually not subjected to invasive study. This has implied a belief that mild angina was associated with less advanced arterial disease than severe angina, and should not be considered for surgical therapy as this is known certainly only to offer symptomatic relief.

This concept needs to be critically reviewed in the light of the increasing knowledge of the determinants of prognosis in angina. It has recently become apparent that one of the most important is the arteriographic severity of the coronary arterial disease. Bruschke et al. (1973a), reviewing the data available from the extensive experience of the Cleveland Clinic concluded that the 5-year mortality for patients with one-vessel disease was 14.6 per cent $(20 \%$ if left anterior descending artery involved), with two-vessel disease the mortality was 37.8 per cent, and with three-vessel disease it was 53.8 per cent.

Oberman and his colleagues (Oberman et al., 1973) have also recently reported their experience; they showed a 95 per cent two-year survival for patients with single-vessel disease but only 70 per cent for those with two or three-vessel disease. In Lichtlen's series (Lichtlen and Moccetti, 1972), with an average follow-up of 33 months, there was a mortality rate of ro per cent for single vessel disease, 18 per cent for double vessel disease, and 34 per cent for triple vessel disease. All these studies have demonstrated that major disease of the left anterior descending artery is associated with a worse prognosis than similar disease of the right coronary or cirumflex artery.

If a group of patients with arteriographically severe disease could be identified, they would be the most suitable candidates for more aggressive therapy, if the latter offered improvement of their relatively poorer prognosis. It is relevant to mention that Sheldon et al. (1973) have recently reported an improved long-term survival in patients with double or triple vessel disease who underwent coronary artery bypass surgery.

Review of the published material has not revealed any previous arteriographic studies of patients with specifically mild angina. There have been several studies correlating angina with arteriographic findings (Paulin, 1964; Proudfit, Shirey, and Sones, 1966; Campeau et al., 1968; Friesinger and Smith, 1972), but all have included both mild and severe cases of angina in the patients investigated. The coronary angiographic findings in our patients were similar to these reports, suggesting that the extent of the coronary disease cannot be judged from the severity of the symptoms.

Because of limitations in community facilities for cardiac catheterization, it would be extremely useful if there were any clinical parameters or simple procedures which might predict the severity of coronary artery disease and thus make it possible to be more selective in choosing patients for coronary arteriography, with its small but definite associated risks.

Electrocardiographic abnormalities have been shown to correlate well with the presence of arteriographic disease. The presence of myocardial infarction pattern on the electrocardiogram is almost always associated with arteriographic abnormalities. The relation of ECG abnormalities to the degree of coronary artery disease, has not, however, been established.

In this series duration of history and electrocardiographic abnormalities were unhelpful in predicting more severe coronary artery disease. The electrocardiogram was shown to be a poor screening test by the fact that II of 22 patients with double or triple vessel disease had normal resting electrocardiograms.

Although a positive pacing test or the combination of positive pacing and exercise tests were statistically significant predicators of severity, these tests would not be very useful clinical aids because of the number of false negatives.

Oberman et al. (1973) in their review noted 4 conditions which were associated with more severe coronary arterial disease, namely, congestive heart failure, cardiac enlargement, hypertension, and electrocardiographic abnormalities. In this series there were no patients with cardiac failure or cardiac enlargement. There were too few patients with hypertension in our group to comment on this point.

Proudfit et al. (1968) have analysed a group of their patients, also seeking discriminating factors. The factors examined were duration of pain, distribution of the pain, factors precipitating pain, and the serum cholesterol. They found that none of these factors selected those with multivessel involvement from patients with exertional angina. Parker, Di Giorgi, and West (1966) have also shown that duration of symptoms did not correlate with arteriographic severity. 
Bruschke et al. (1973b) have analysed prognostic factors in a more recent study from the Cleveland Clinic. They found that the 5-year mortality rose with the severity as well as the duration of symptoms, and especially with a combination of these factors, but there was no consistent relationship for cases with duration of symptoms less than one year. They concluded that differences in mortality were partly related to arteriographic differences. They also found that the 5-year mortality rate was directly related to the presence and the number of infarcts, because of both the higher percentage of multivessel involvement and the angiographic abnormalities of the left ventricle in these patients.

Unfortunately, all these possible discriminants have limited clinical application because of the high number of false negatives which occur. This applies especially to the management of the individual patient with mild angina.

\section{Conclusions}

It is concluded: ( $I$ ) mild angina may be a manifestation of severe coronary artery disease; (2) arteriographic severity cannot be accurately predicted from the clinical findings or with the aid of simple investigative procedures.

We would like to thank Dr. M. Honey for allowing us to include his patients.

\section{References}

Bruschke, A. V. G., Proudfit, W. L., and Sones, F. M., Jr. (1973a). Progress study of 590 consecutive nonsurgical cases of coronary disease followed 5-9 years: I. Arteriographic correlations. Circulation, 47, I 147.
Bruschke, A. V. G., Proudfit, W. L., and Sones, F. M., Jr. (1973b). Progress study of 590 consecutive nonsurgical cases of coronary disease followed $5-9$ years: II. Ventriculographic and other correlations. Circulation, 47, II 54.

Campeau, L., Bourassa, M. G., Bois, M. A., Saltiel, J., Lesperance, J., Rico, O., Delcan, J. L., and Telleria, M. (1968). Clinical significance of selective coronary cinearteriography. Canadian Medical Association fournal, 99, 1063.

Friesinger, G. C., Page, E. E., and Ross, R. S. (1970). Prognostic significance of coronary arteriography. Transactions of the Association of American Physicians, 83, 78.

Friesinger, G. C., and Smith, R. F. (1972). Correlation of electrocardiographic studies and arteriographic findings with angina pectoris. Circulation, 46, II 73.

Lichtlen, P. R., and Moccetti, T. (1972). Prognostic aspects of coronary angiography (abstract). Circulation, 45-46, Suppl. II, II-7.

Oberman, A., Jones, W. B., Riley, C. P., Reeves, T. J., Sheffield, L. T., and Turner, M. E. (1973). Natural history of coronary artery disease. Bulletin of the New York Academy of Medicine, 48, I rog.

Parker, J. O., Di Giorgi, S., and West, R. O. (1966). Selective coronary arteriography: arteriographic patterns in coronary heart disease. Canadian Medical Association fournal, 95, 291.

Paulin, S. (1964). Coronary angiography: a technical anatomic, and clinical study. Acta Radiologica, Suppl. 233, I.

Proudfit, W. L., Shirey, E. K., Sheldon, W. C., and Sones, F. M., Jr. (1968). Certain clinical characteristics correlated with extent of obstructive lesions demonstrated by selective cine-coronary arteriography. Circulation, 38, 947.

Proudfit, W. L., Shirey, E. K., and Sones, F. M., Jr. (I966). Selective cine coronary arteriography: correlation with clinical findings in 1,000 patients. Circulation, 33, 901 .

Proudfit, W. L., Shirey, E. K., and Sones, F. M. (I963). Distribution of arterial lesions demonstrated by selective cinecoronary arteriography. Circulation, 36, 54.

Sheldon, W. C., Rincon, G., Effler, D. B., Proudfit, W. L., and Sones, F. M., Jr. (1973). Vein graft surgery for coronary artery disease: survival and angiographic results in I,000 patients. Circulation, 47-48, Suppl. III, 184.

Requests for reprints to Dr. R. Balcon, The London Chest Hospital, Bonner Road, London E2 9JX. 